\title{
Thermal and tensile mechanical behavior of acetic anhydride treated silk fibres
}

\author{
Md. Minhaz-Ul Haque*, Mst. Ayesha Akther Zaman, M. H. Rahaman, M. Z. Hossain, \\ M. Maniruzzaman
}

Dept. of Applied Chemistry and Chemical Technology, Islamic University Kushtia-7003, Bangladesh

Email address:

Minhaz1978@yahoo.com (M. Minhaz-U1 Haque)

To cite this article:

Md. Minhaz-Ul Haque, Mst. Ayesha Akther Zaman, M. H. Rahaman, M. Z. Hossain, M. Maniruzzaman. Thermal and Tensile Mechanical Behavior of Acetic Anhydride Treated Silk Fibres. International Journal of Materials Science and Applications.

Vol. 3, No. 3, 2014, pp. 106-110. doi: 10.11648/j.ijmsa.20140303.16

\begin{abstract}
Acylation of fibres can provide a route to have materials with better water proofing capability. In our present study, silk fibres were treated with various concentration $(5,10$ and $15 \mathrm{wt} . \%)$ of acetic anhydride aqueous solution and then thermal properties, tensile mechanical behaviour and moisture content of acetic anhydride treated silk fibres were studied. Raw silk fibres were taken as control for comparison. It was found that elastic modulus and tensile strength of silk fibres were increased with increasing acetic anhydride concentration while elongation at break was decreased with increase of acetic anhydride content in solution. Silk fibres treated with $15 \mathrm{wt}$. \% of acetic anhydride solution exhibited about 141\% (from 17 $\mathrm{GPa}$ to $41 \mathrm{GPa}$ ) improvement in elastic modulus. It was also found that acetic anhydride treated silk fibres displayed higher thermal resistance and lower moisture content as compared to untreated silk fibres.
\end{abstract}

Keywords: Acetic Anhydride Treatment, Moisture Content, Silk Fibres, Tensile Properties, Thermal Behaviour

\section{Introduction}

Silk is a very high quality natural fibre. Still today, no other natural fibre is as good as silk. Silk is called the "Queen of fibres" because of its lightness, fineness, as well as strength [1]. It is versatile and can be used in making sportswear, dress of men and women, decorator fabrics for home and office etc. Recently, silk fibres are also being used in composite materials as reinforcement [2].

Silk is a continuous protein fibre produced by the silkworm so as to from its cocoon [3]. The main constituents of silk fibre are fibroin $(75 \%)$ and sericin $(25 \%)$. Fibroin is a crystalline protein, while sericin is an amorphous protein. Fibroin consists of roughly $76 \%$ of amino acids with non-polar side chains and only about $21 \%$ of polar groups. In sericin, however, the ratio is about $25 \%$ of non-polar groups and about $75 \%$ of polar side chains [4]. The chemistry of silk reveals that it possesses both acidic and basic properties, because silk is a protein fibre, which is composed of amino acids. Carboxyl (-COOH), amino $\left(-\mathrm{NH}_{2}\right)$ and hydroxyl $(-\mathrm{OH})$ side groups were reported as the main reactive sites in silk fibres interacting with vinyl monomers, epoxy compounds and dibasic acid anhydrides [5].

Silk fibres are valued for the outstanding characteristics that have exploited for the production of precious textile goods. However, silk possesses some inferior textile performances, such as photoyellowing, antiyellowing, wash and wear, abrasion resistance, crease proofing properties, dimensional stability, oil and water repellency etc. The characteristics of silk can be improved by various physical, chemical, enzymatic etc. modification techniques. Physical modification e.g. plasma, corona [6, 7] applications may expose and generate functional groups on the protein surface. Enzymatic treatments have been utilised to improve properties such as shrink resistance. In case of enzymatic modification, proteases, the main class of enzyme are used for modifying protein fibre surfaces [8].

Among the various methods available for the modification of silk, chemical modification appear attractive and are recently used in industrial applications. Khan et al. treated silk fibres with 30 wt.\% of citric acid and reported that tensile strength of silk fibres was improved by this treatment [9]. Several researchers carried out grafting of vinyl monomers onto silk fibres to improve mechanical and surface properties of silk fibres such as grafting of 2-hydroxyethylmethacrylate (HEMA), methacrylamide (MAA) [10], methacrylonitrile (MAN) [11, 12], 2-methacryloyloxyethyl phosphorylcholine (MPC) 
[13], methylmethacrylate (MMA), ethylmethacrylate (EMA)

[12] etc. onto silk fibres.

Other chemical approaches utilised to modify protein fibres include bleaching (hydrogen peroxide, sodium borohydride, sodium bisulfite, thiourea, oxalic acid etc. were utilised in protein-fibre bleaching [14, 15]), chlorination [16], polymer deposition (to generate improved biomaterials from silk fibroin, cyanuric chloride-activated poly(ethylene glycol) has been applied to give increased hydrophilicity and a smoother morphology [17]) etc.

Another important chemical modification of silk fibres is acylation. Acylation may provide a route to water-proofing of materials such as wool and silk. Arai et al. [18] and Davarpanah et al. [19] carried out anhydride treatment onto silk fibres using succinic anhydride and phthalic anhydride and reported that acylation provides an enhanced surface for the grafting of chitosan to silk to provide antibacterial and anti-felting properties and superior dyeing ability in an environmentally friendly fashion.

Our aim is to develop silk fibre with better physical and mechanical properties by chemical modification or surface treatment for a wide range of applications. Therefore, in the present work, silk fibres were treated with acetic anhydride of various concentrations (5-15\%) and thermal and tensile mechanical behaviour of treated silk fibres were studied.

\section{Materials and Methods}

\subsection{Materials}

Mulberry raw silk fibres were collected from Bangladesh Sericulture Research and Training Institute (BSR \& TI), Rajshahi, Bangladesh. Acetic anhydride for chemical modification was purchased from BDH, England. Acetic acid, purity $97 \%$ was purchased from Merck, Germany.

\subsection{Acetic Anhydride Treatment of Silk Fibres}

The raw silk fibres $(10 \mathrm{~g})$ were immersed in glacial acetic acid $(150 \mathrm{ml})$ in a stopper bottle for 1 hour at $25^{\circ} \mathrm{C}$. The mixture was shaken occasionally and the fibres were pressed out on a Buchner funnel. The fibres were then soaked in $180 \mathrm{ml}$ of acetic anhydride solution (5-15 wt.\%) containing one $\mathrm{ml}$ of concentrated $\mathrm{H}_{2} \mathrm{SO}_{4}$ at $25{ }^{\circ} \mathrm{C}$. The mixture was shaken vigorously for $1 \mathrm{~min}$ and then $10 \mathrm{ml}$ of anhydride solution (5-15 wt.\%) was added. The mixture was shaken again vigorously for about $1 \mathrm{~min}$ and $10 \mathrm{ml}$ of anhydride solution (5-15 wt.\%) was added again. The resultant mixture was held for $5 \mathrm{~min}$ at $25^{\circ} \mathrm{C}$. Finally, the fibres were taken out, washed well with distilled water and dried in an oven at $80{ }^{\circ} \mathrm{C}$ for 6 hours. The reaction shown in the reaction scheme of Figure 1 was expected by anhydride treatment of silk fibre.

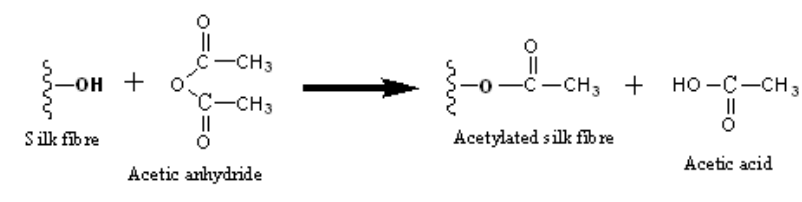

Figure 1. Reaction scheme of acetic anhydride with OH group of fibre.

\subsection{Analytical Techniques}

Hounsfield UTM 10KN (H10KS) was used for tensile mechanical tests of fibres. A variety of methods are used to measure the tensile strength of single fibre. For high modulus fibre, there is an ASTM standard test method (D3379-75) named Single fibre Pull-Out test. Silk fibre is a high modulus fibre so, its test was carried out by this method. Individual fibres were glued across a window in a thin card, another card was glued to it. The card was gripped in the jaws of tensile machine, the sides of the card window frame was cut carefully to leave the fibre free and loaded it to failure at a slow crosshead speed [20]. The diameter of each specimen was measured using an optical microscope. Tensile strength, elastic modulus and elongation at break were determined by this test.

Thermogravimetric analysis (TGA) and Differential thermal analysis (DTA) of raw silk fibres and anhydride treated silk fibres were carried out in a TG/DTA (SII-6300 analyzer). The samples $(4-10 \mathrm{mg})$ were heated from 30 to $600{ }^{\circ} \mathrm{C}$ at $20{ }^{\circ} \mathrm{C} \mathrm{min}^{-1}$ under nitrogen, after equilibrating at $50{ }^{\circ} \mathrm{C}$. The change of weight percent and its derivative (DTG) were recorded as a function of temperature.

The moisture content of raw and anhydride treated silk fibres was measured by using computerized Moisture analyzer (KERN RH NO-3) machine. The raw and treated silk fibres were placed in the machine and the amount of moisture in the fibres were observed. Maximum capacity of this analyzer was $120 \mathrm{~g}$.

\section{Results and Discussion}

\subsection{Tensile Properties}

Figure 2 represents the elastic modulus of raw silk and acetic anhydride treated silk fibres. The raw silk fibres were used as control for comparison. The acetic anhydride treated silk fibres displayed higher values of elastic modulus (Figure 2) than untreated raw silk fibres. This improvement in elastic modulus of silk fibres may be attributed to the strong bond formation between hydroxyl groups of sericin and acetic anhydride. Sericin is a natural macromolecular protein. It consists of 18 amino acids. Most of these amino acids have strong polar side group such as hydroxyl, carboxyl and amino groups [21]. 


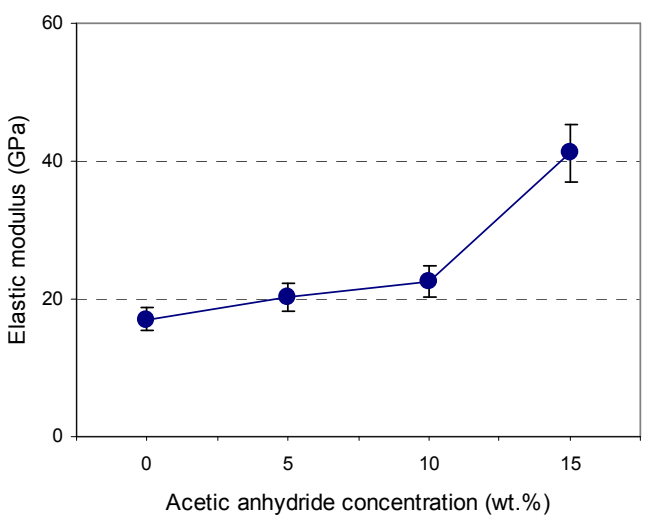

Figure 2. Elastic modulus of raw silk fibres and anhydride (5\%,10\% and $15 \%)$ treated silk fibres.

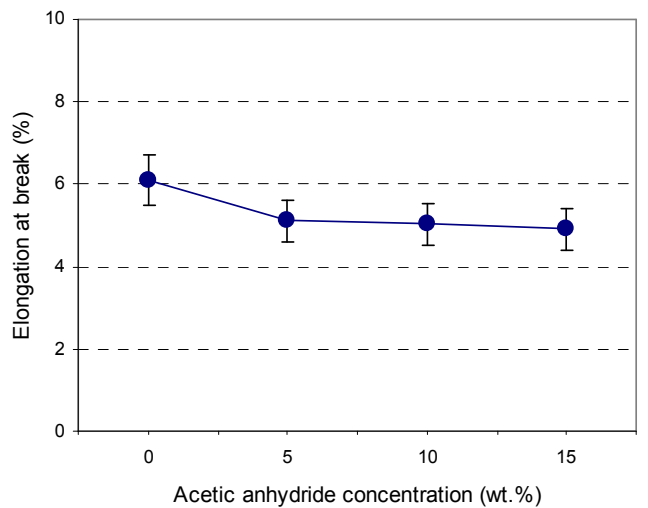

Figure 3. Elongation or srain of raw silk fibres and anhydride (5\%,10\% and $15 \%)$ treated silk fibres.

It is also seen in Figure 2 that elastic modulus of silk fibres were increased with increasing anhydride concentration, while elongation at break (Figure 3) was decreased with increasing of anhydride content in solution. The elongation at break of anhydride treated fibres was decreased because of increasing of fibres stiffness. The tensile properties (tensile strength 300-600 MPa and tensile modulus 9-17 GPa) of Bombyx mori silk fibres were reported elsewhere by Perez-Rigueiro et al [22] and Gosline et al [23]. It was found that silk fibres treated with 15 wt.\% of anhydride solution improved the tensile modulus about $141 \%$ (from $17 \mathrm{GPa}$ to $41 \mathrm{GPa}$ ).

\subsection{Thermogravimetrical Analysis}

From TGA testing, thermogravimetric (TG) curves (Figure 4) and derivative thermogravimetry (DTG) curves (Figure 5) as a function of temperature of (a) raw silk fibre, (b) 5\% anhydride treated silk fibres, (c) $10 \%$ anhydride treated silk fibres, (d) $15 \%$ anhydride treated silk fibres, analyzed at $20{ }^{\circ} \mathrm{C} \mathrm{min}^{-1}$ in nitrogen, were obtained. Raw silk fibers were degraded through two main stages: (i) in between $50{ }^{\circ} \mathrm{C}$ to $110{ }^{\circ} \mathrm{C}$ showing maximum degradation rate at about $72{ }^{\circ} \mathrm{C}$ due to removal of volatile matter and the absorbed moisture from the silk fibres and (ii) in between $280{ }^{\circ} \mathrm{C}$ to $352{ }^{\circ} \mathrm{C}$ showing maximum degradation rate at about $314.9{ }^{\circ} \mathrm{C}$ due to the degradation of silk fibres. For raw silk fibres maximum degradation rate was recorded at about $314.9{ }^{\circ} \mathrm{C}$, similar degradation rate of silk fibres was

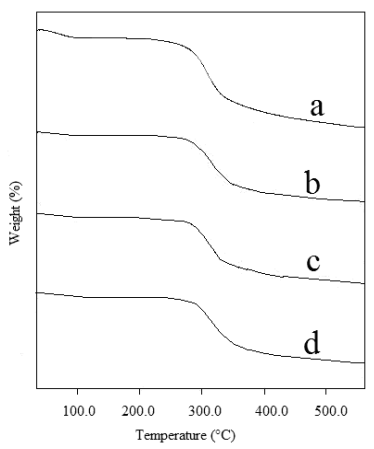

Figure 4. TG curves of (a) raw silk fibres, (b) 5\% anhydride treated silk fibres, (c) 10\% anhydride treated silk fibres, (d) 15\% anhydride treated silk fibres.

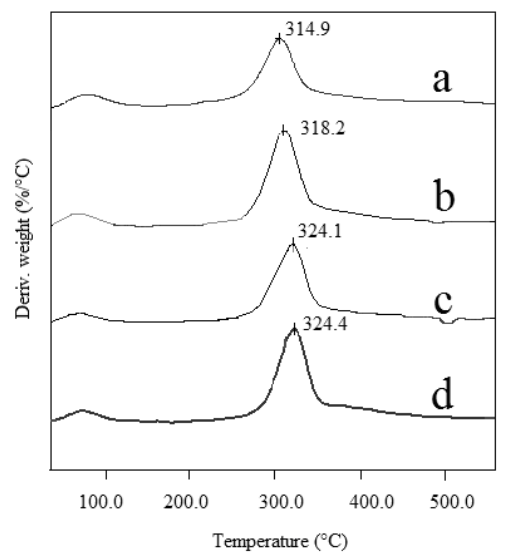

Figure 5. DTG curves of (a) Raw silk fibres, (b) $5 \%$ anhydride treated silk fibres, (c) 10\% anhydride treated silk fibres, (d) 15\% anhydride treated silk fibres.

also reported by Kameda et al. [24]. In the Figure 5, it is also seen that raw silk fibres showed lower value of $T_{d}\left(T_{d}\right.$, temperature showing maximum degradation rate) than that of anhydride treated silk fibres. Therefore, it can be deduced that anhydride treatment of silk fibres can improve the thermal resistance of silk fibres.

Thermal degradation behaviour of raw silk fibres and anhydride treated silk fibres was further supported by differential thermal analysis (DTA) (Figure 6). DTA is a technique by which phase transition or chemical reactions can be followed through observation of heat absorbed or liberated. With constant heating, any transition or thermally induced reaction in the sample is recorded as a peak or dip in an otherwise straight line. An endothermic process causes the thermocouple junction in the sample to lag behind the junction in the reference material, and hence develop a voltage, whereas an exothermic event produces a voltage of opposite sign. It is seen in the Figure 6 that each curve displays the two endothermic peaks - the first peak at about $70-80{ }^{\circ} \mathrm{C}$ may correspond to removal of volatile matter as well as moisture and the second peak at about $314-324{ }^{\circ} \mathrm{C}$ corresponds to the thermal degradation of silk fibres. 


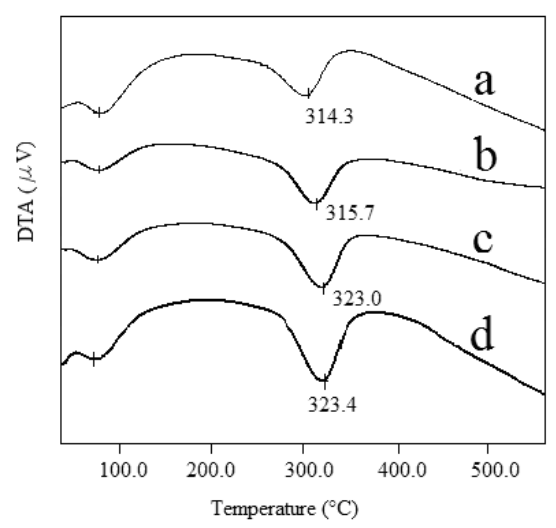

Figure 6. DTA curves of (a) Raw silk fibres, (b) 5\% anhydride treated silk fibres, (c) 10\% anhydride treated silk fibres, (d) 15\% anhydride treated silk fibres.

\subsection{Effect of Anhydride Treatment on Moisture Content of Silk Fibres}

Figure 7 shows the moisture content of raw silk fibres and acetic anhydride treated silk fibres. Sericin - one of the major components of raw silk fibre - consists of 18 amino acids. Most of these amino acids have strong polar side group such as hydroxyl, carboxyl and amino groups. Hence, raw silk fibres have high affinity towards moisture. Raw silk fibres contain about 14 wt.\% of moisture, on the other hand anhydride treated silk fibres displayed lower moisture content (about 9.16 wt.\%) as compared to raw silk fibres. Due to anhydride treatment the polar side groups of amino acids in sericin are linked with acetic anhydride. Consequently, hydrophobicity of silk fibres surfaces increased. Hence the moisture content of acetylated silk fibre decreases with increase of anhydride concentration.

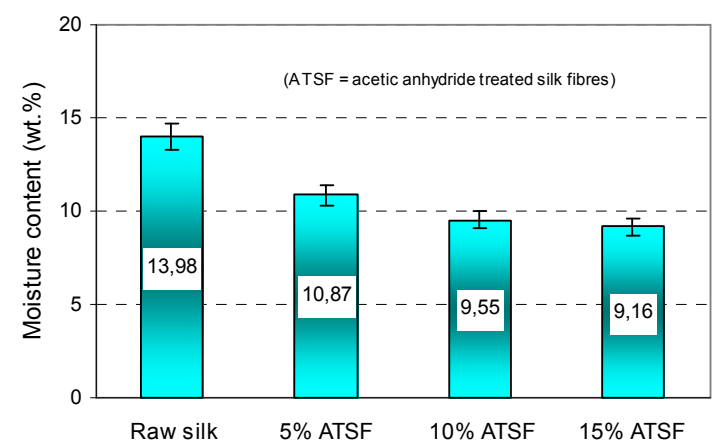

Figure 7. Effect of anhydride (5-15 wt.\%) treatment on moisture content of silk fibres.

\section{Conclusions}

Thermal properties, tensile mechanical behaviour and moisture content of silk fibres treated with acetic anhydride of various concentrations were studied. Elastic modulus and elongation at break percentage of silk fibres were found to be affected by acetic anhydride treatment. It was found that silk fibres treated with 15 wt.\% of anhydride solution displayed about $141 \%$ improvement in elastic modulus.
Anhydride treated silk fibres also exhibited higher thermal resistance and lower moisture content as compared to untreated silk fibres. Therefore, it can be concluded that acetic anhydride treatment of silk fibres has a positive impact on the tensile mechanical properties and thermal resistance of silk fibres. These treated silk fibres with better physical and mechanical properties may be used in textiles, medical and other special applications.

\section{References}

[1] M. L. Joseph, Introductory Textile Science, 3rd ed., Holt, Rinehart and Winston, New York, 1976, pp. 13, 104-111.

[2] J. G. Hardy, and T. R. Scheibel, Composite materials based on silk proteins, Progress in Polymer Science 35 (2010) 1093-1115.

[3] H. R. Mauersberger, Matthew's Textile Fibres, John Wiley \& Son Inc., New York, 1954, pp. 753-754.

[4] .M. Li, S. Lu, Z. Wu, H. Yan, J. Mo, and L. Wang, Study on Porous Silk Fibroin Materials, Journal of Applied Polymer Science 79 (2001) 2185-2191.

[5] M. Tsukada, H. Shiozaki, and G. Freddi, Chemical modification of bombyx mori silk fibres - scientific aspects and technological applications, Melliand Textilberichte International Textile Reports 74 (1993) 778.

[6] H. Hocker, Plasma treatment of textile fibers, Pure and Applied Chemistry 74 (2002) 423-427.

[7] A. Ceria, G. Rovero, S. Sicardi, and F. Ferrero, Atmospheric continuous cold plasma treatment: Thermal and hydrodynamical diagnostics of a plasma jet pilot unit, Chemical Engineering and Processing: Process Intensification 49 (2010) 65-69.

[8] N. Duran, and M. Duran, Enzyme applications in the textile industry, Review of Progress in Coloration and Related Topics 30 (2000) 41-44.

[9] M. M. R. Khan, M. Tsukada, Y. Gotoh, H. Morikawa, G. Freddi, and H. Shiozaki, Physical properties and dyeability of silk fibers degummed with citric acid, Bioresource Technology 101 (2010) 8439-8445.

[10] M. Tsukada, Structural characteristics of 2-hydroxymethacrylate/MAA grafted silk fibre, Journal of Applied Polymer Science 35 (1988) 2133-2140.

[11] M. Tsukada, and H. Shiozaki, Characterisation of methacrylonitrile grafted silk fibres, Journal of Applied Polymer Science 39 (1990) 1289-1297.

[12] M. R. K. Sheikh, F. I. Farouqui, S. Momin, and G.M. S. Rahman, Grafting of silk fibre with MMA, EMA and MAN for improved properties, Journal of Applied Sciences 6 (2006) 1954-1958.

[13] T. Furuzono, K. Ishihara, N. Nakabayashi, and Y. Tamada, Chemical modification of silk fibroin with 2-methacryloyloxyethyl phosphorylcholine. II. Graft-polymerization onto fabric through 2-methacryloyloxyethyl isocyanate and interaction between fabric and platelets, Biomaterials 21 (2000) 327-333. 
[14] M. Arifoglu, W. N. Marmer, and R. Dudley, Reaction of thiourea with hydrogen peroxide:13C NMR studies of an oxidative/reductive bleaching process, Textile Research Journal 62 (1992) 94-100.

[15] D. Yilmazer, and M. Kanik, Bleaching of wool with sodium borohydride, Journal of Engineered Fibers and Fabrics 4 (2009) 45-50.

[16] K. Roeper, J. Foehles, D. Peters, and H. Zahn, Morphological composition of the cuticle from chemically treated wool part II: the role of the cuticle in industrial shrink proofing processes, Textile Research Journal 54 (1984) 262-270.

[17] C. Vepari, D. Matheson, L. Drummy, R. Naik, and D. L. Kaplan, Surface modification of silk fibroin with poly(ethylene glycol) for antiadhesion and antithrombotic applications, Journal of Biomedical Materials Research - Part A 93 (2010) 595-606.

[18] T. Arai, Freddi, R. Innocenti, D. L. Kaplan, and M. Tsukada, Acylation of silk and wool with acid anhydrides and preparation of water-repellent fibers, Journal of Applied Polymer Science 82 (2001) 2832-2841.
[19] S. Davarpanah, N. M. Mahmoodi, M. Arami, H. Bahrami, and F. Mazaheri, Environmentally friendly surface modification of silk fiber: Chitosan grafting and dyeing, Applied Surface Science 255 (2009) 4171-4176.

[20] ASTM Designation (D3379-75) Standard Test Method named Single fibre Pull-Out Test for fibre.

[21] B. Lotz, and F. Cesari, The Chemical Structure \& the Crystalline Structures of Bombyx mori silk Fibroin, Biochimie 61 (1979) 205-214.

[22] J. P. Rigueiro, M. Elices, J. Llorca, and C. Viney, Effect of degumming on the tensile properties of silkworm (Bombyx mori) silk fiber, Journal of Applied Polymer Science 84 (2002) 1431-1437.

[23] J. M. Gosline, P. A. Guerette , C. S. Ortlepp, and K. N. Savage, The mechanical design of spider silks: from fibroin sequence to mechanical function,Journal of Experimental Biology 202 (1999) 3295-3303.

[24] T. Kameda, and M. Tsukada, Structure and Thermal Analyses of MAA-Grafted Silk Fiber, Macromolecular Materials and Engineering 291 (2006) 877. 